\title{
Mental Retardation an Overview
}

\section{ABSTRACT:}

\author{
Dr. Thiyam Kiran Singh ${ }^{1}$, Arya Arvind ${ }^{2}$
}

There are limited numbers of studies which have evaluated mental retardation in a complete way. This article reviews the existing literature and electronic searches available regarding mental retardation. This article deals with mental retardation, definitions, types, brain defects causing retardation, some organic syndromes associated with retardation, screening tools used and a brief view on treatment methods used by Psychologist.

Keywords: Mental Retardation, Treatment, Screening Tools, Overview

\section{INTRODUCTION:}

The earliest reference to intellectual disability dates to the Egyptian Papyrus of Thebes in 1552 B.C. In 18th century people with no adequate social skills and mild intellectual disability received little or no special attention and those with severe intellectual disability was cared in monasteries .In late $18^{\text {th }}$ century Jean-Marc Itard was credited with creating the first systematic intervention program for a People with Intellectual Disability in France First residential facility for intellectually disabled was founded in mid $19^{\text {th }}$ century in Switzerland. Initial attempts to develop classifications for mental illness in the late 19th century were based on etiological and physical correlates of observable traits, followed by differentiation based on level and severity of cognitive impairment. The term 'mental retardation' was used by the American Association of Mental Retardation (AAMR) for the first time in 1961. Psychological tests to assess intelligence were developed in the 20th century

The AAMD (1983) states that "Mental retardation refers to a significantly sub-average general intellectual functioning resulting in or associated with concurrent impairments in adaptive behavior and manifested during the developmental period". It is a more functional definition which stresses the interaction between the person's capabilities, the environment in which the individual functions and the need for support systems. The AAMR (1992) defined mental retardation as manifesting before age 18 , refers to a substantial limitations in present functioning, characterized by significantly sub-average intellectual functioning which exists concurrently with related limitations in two or more of the following adaptive skill areas: communication, -

\footnotetext{
${ }^{1}$ Associate Professor, Department of Psychiatry, Govt. Medical College and Hospital, Chandigarh) Editor, IJIP

${ }^{2}$ Mphil Clinical Psychology trainee, Department of Psychology, AIBAS, Amity University Rajasthan, Jaipur
} 


\section{Mental Retardation an Overview}

- self- care, home living, social skills, community use, self- direction, health and safety, functional academics, leisure and work. American Psychiatric Association(2000) states that mental retardation is significantly sub average general intellectual functioning that is accompanied by significant limitations in adaptive functioning in certain skill areas such as selfcare, work, health and safety.

Adaptive functioning can be defined as mastering childhood skills like toileting, dressing, understanding concept of time and money, able to use tools, to shop, to travel alone in public transport and become socially responsive. For example an adolescent is expected to be able to apply academic skills, reasoning and judgment to daily living and participation in group activities. An adult is expected to be self-supporting and assume social responsibilities. There are many tests to measure adaptive behavior. Adaptive Behavior Scale (Nihiria et al 1975) and Vinland Adaptive Behavior Scale (Sparrow, Ballo \& Cicchetti, 1984) are two among them.

General intelligence is defined as capacity of individual to perceive, think, understand object outside him and react without confusion and perform activities successfully and adjust himself in social situation without conflict

\section{AMERICAN ASSOSIATION ON INTELLECTUAL \& DEVELOPMENTAL DISABILITY}

American Association on Intellectual \&DevelopmentalDisability is functioning since 1876.Misson of this organization is to promote positive policies, sound research, effective practices and universal human right for people with intellectual disability. In 2006 changed name to American Association of Mental Retardation. In 10 th edition of AAIDD (2002) a new definition was given to Mental retardation i.e. Mental retardation can be defined as disability characterized by significant limitation in both intellectual functioning and adaptive behavior as expressed in conceptual, social and practice adaptive skills

5 Assumptions essential for application of definition

* Limitations present in functional must be considered with in context of communicative environment typical of individuals age, peers and culture

* Valid assessment consider cultural and language diversity as well as difference in community, sensory motor and behavioral factor

* Within an individual limitations co-exist with strength

* An important purpose of describing limitations to develop profile need support

* With appropriate personalized support over sustained period, life functioning of person with mental retardation improve 


\section{Mental Retardation an Overview}

\section{Types of Mental Retardation:}

\section{Mild Mental Retardation}

$75 \%$ to $90 \%$ of all cases of retardation constitute mild mental retardation. They are educable. Function at one half to two thirds of CA (IQ range 50-69). They may have no unusual physical signs and can acquire practical skills. Acquire language for delay but able to use speech for every day purposes. Difficulty in academic school work, reading and writing are present. Mild Mentally Retarded people are Integrated into general society. Intellectual level of mild mentally retarded as adult is comparable to those of average 8 to 11 year old children

In preschool children there will be no obvious conceptual differences for school going children there will be difficulties in learning and too meet age related expectations.In adults short term memory,abstract thinking, executive function are impared. They are immature in social interactions and in controlling emotions. These type of children need support

\section{Moderate Mental Retardation}

$7 \%$ of all cases of retardation constitute moderate mental retardation. They are trainable. Function at one third to one half of CA (IQ: 35 to 49). They have noticeable delays, especially in speech. May have some unusual physical signs (clumsy, ungainly, deformities and poor motor coordination).They Can learn simple communication, elementary health and safety habits, can participate in simple activities and self-care, perform tasks in sheltered conditions and Can travel alone to familiar places. They can attain intellectual level similar to those of average 4 to 7 year old children.They have lagged conceptual skills. Need assistance in day to day tasks. Significant social and communication skills are lagged. By teaching and training individual can be independed in fulfilling personal needs.

\section{Severe Mental Retardation}

$3 \%$ of all cases of Mental retardation constitute of severe mental retardation. Function at one fifth to one third of CA (IQ: 20 to 34). They are Dependent retarted. Have Marked and obvious delays; may walk late. Little or no communication skills but may have some understanding of speech and show some response. Their speech and communication is focused on here and now with in everyday events. They can be taught daily routines and repetitive activities can be trained in simple self-care. Such kind of children need direction and supervision. They can develop limited levels of personal hygiene and self help skills. Attainment of concepts in severely mentally retarded will be limited. 


\section{Mental Retardation an Overview}

\section{Profound Mental Retardation}

$1 \%$ of all cases of mental retardation constitute profound mental retardation. They function less than one fifth of CA (IQ: < 20). They have marked delays in all areas. Congenital abnormalities often present. Often need attendant care. So they are called Life support retarded or custodial. They respond to regular physical activity and social stimulation and not capable of self-care. Conceptual skills generally involve physical world than symbolic process. Individuals use objects in goal directed manner. Motor and sensory impairments may prevent functional use of objects. Individuals have very limited understanding of speech and gesture. Individuals will enjoy interaction with family members and care takers.

\section{Brain Defects in Mental Retardation}

Some cases of mental retardation occur in association with known organic brain pathology (kaski, 2000). Profound retardation, which fortunately is rare, always includes obvious organic impairment. Genetic Chromosomal Factors, Infections and toxic agents, Trauma (physical injury) Ionizing radiation are some factors which cause mental retardation.

\section{Genetic Chromosomal Factors:}

Genetic chromosomal factors play a major role in severe mental retardation, down's syndrome, fragile x. Genetic aberrations are responsible for metabolic alterations that adversely affect the brain development involve many other developmental anomalies besides mental retardation- for eg:- autism. Mental retardation associated with known genetic chromosomal defects is moderate to severe

\section{Infections and Toxic Agents:}

Mental retardation can also be associated with wide range of conditions due to infection such as viral encephalitis, or genital herpes (kaski, 2000). If a pregnant lady is infected with syphilis or HIV-1 or if she gets German measles, her child may suffer brain damage. We are in developing world where pollution and electronic goods rule our world. Increased level of Carbon Monoxide can lead to brain damage and thus cause mental retardation. If pregnant lady took drugs or alcohol then child have more chances to be mentally retarded.

\section{Ionizing Radiation:}

Powerful radiation can damage sex cells, other body cells and tissues.Each and every country in this world is trying to be number one in Nuclear weapons. So they are conducting tests to improve their weapons but these kind of testing are harmful for human beings. We have a perfect example of Nagasaki and Hiroshima. Then Leakages at nuclear power stations like what happened in Bhopal. In a race to rule the world we are destroying dreams of thousands of unborn babies. 


\section{Mental Retardation an Overview}

\section{Trauma (Physical Injury)}

Physical injury at birth can result in mental retardation (kaski, 2000).Malposition of fetus andbleeding within the brain can also cause mental retardation. Hypoxia i.e lack of sufficient oxygen in brain can also result mental retardation

\section{Malnutrition}

Dietary deficiencies in protein and other essential nutrients in early development of fetus could do irreversible physical and mental damage. Malnutrition can affect child's responsiveness, curiosity and motivation to learn (Ricciuti, 1993)

\section{Organic Retardation Syndromes}

Mental retardation stemming from biological causes can be classified into several recognizable clinical types. Down Syndrome, Phenylketonuria, Cranial Anamolies are also associated with mental retardation

\section{A) DOWNS SYNDROM}

Downs syndrome was first described by Langdon Down(1866). It is associated with severe and moderate mental retardation. 1 in every 1000 babies is diagnosed as having downs syndrome. This creates irreversible limitations on survivability, intellectual achievement and competence in managing life task. Adaptive abilities will decrease with increasing age, especially after 40. Flat facial profile, almond shaped eyes, abnormally thick eyelids, face and nose are often flat and broad, large mouth, Iris of eye is frequently specked, small ears, curving fifth fingers, single transverse palmar creases are the characteristics of downs syndrome. Children also have slow growth, congenital heart defect, thyroid dysfunction, developmental delay, especially in speech. Trisomy in $21^{\text {st }}$ chromosome or late conception can be a reason for downs syndrome.

\section{C) CRANIAL ANOMALITIES}

Mental retardation is associated with number of conditions that involve alterations in head size and shape and for which the causal factors have not been definitely established.

i) Macrocephaly: Large headedness, Increase in size and weight of brain, Enlargement of skull, Visual impairment, Convulsions

ii) Microcephaly: Small headedness, Cranium fail to attain normal size, Head circumference will be less than 17 inches and normal size is 22 inch, Penrose(1963) described that microcephaly children have normal musculature and sex organs, Skull will be cone shaped, they have receding chin and forehead

iii) Hydrocephaly: Abnormal amount of CSF with in cranium causes damage to brain tissues and enlargement of skull.Head can be enlarged at birth or begins to enlarge soon after as a result of absorption or circulation of CSF. Can arise in 


\section{Mental Retardation an Overview}

infancy/early childhood following development of tumor, subdural hematoma, meningitis. This results in convolutions, Impairment or loss of sight/hearing

\section{MENTAL RETARDATION IN INDIA}

In pre-colonial India Mughal rulers exemplified as protectors, established charity homes for persons with disabilities and provided care and protection for needy. After Mughal rule colonial rule changed those patterns by shifting these people to asylums from community inclusive settings. It was at the Madras Lunatic Asylum, renamed the Institute of Mental Health, that persons with mental illness and those with mental retardation were segregated and given appropriate treatment. Special schools were started for those who could not meet the demands of the mainstream schools .The first residential home for persons with mental retardation was established in Mumbai, then Bombay. Followed by the establishment of a special school in 1944. Subsequently, 11 more schools were established in other parts on India. In 1950 there were only 10 special schools and now there are more than 3000 special schools in our country. From this we could understand that people have understood the value of special school education. The Indian Education Commission, 1964-66 made a clear mention of the presence of only 27 schools for persons with mental retardation in the entire country at that time. In 1953, training teachers to teach persons with mental retardation was initiated in Mumbai by Mrs. Vakil. In 1971, special education to train persons with mental retardation was introduced in Chennai at the BalaVihar Training School by Mrs. M. ClubwalaJadhav. In the same year, the Dilkush Special School was established in Mumbai initiating special teachers' training programs

\section{INDIAN SCREENING TOOLS}

i) Developmental Screening Test (DST) by Bharat Raj is a widely used screening tool by professionals.

ii) Upanayan Early Intervention Programming System (1987).

iii) Functional Assessment Check List for Programming (FACP) 1991.

iv) The revised Madras Developmental Programme System Behavioural Scale MDPS-A curriculum based assessment checklist (1975) is suitable for identification purposes

\section{POLICIES AND PROGRAMMES}

$\nabla \quad$ The National Policy for Children, 1974

$\nabla$ Integrated Education of Disabled Children (IEDC), 1974

$\nabla$ The National Policy on Education (NPE) formulated earlier and was acted upon in May 1986.

$\nabla$ The International Year for the Disabled Persons (IYDP), 1981

$\nabla \quad$ Project Integrated Education for Disabled (PIED), 1987

$\nabla \quad$ Mental Health Act, 1987

$\nabla$ The Program of Action, 1992

$\nabla$ The Persons with Disabilities (Equal Opportunities, Full Participation and Protection of Rights) Act, 1995 
$\nabla$ The Economic and Social Commission for Asia and Pacific (ESCAP)

$\nabla$ The National Trust for Welfare for Persons with Autism, Cerebral Palsy, Mental Retardation and Multiple Disabilities Act, 1999

\section{TREATMENT}

Many types of techniques are used in treating mentally retarded children. Residence treatment which was started in 1960 in which Medical care was provided and house hold routines were practiced. Then behavioral treatment in which behavioral objectives defined and skills are taught in small sequential steps i.e food, toilet etc. This is also used to reduce inappropriate behavior. Cognitive treatment and computer assisted education are also used in training children.

\section{BEHAVIOR MODIFICATION}

There are five major steps in implementing a behavior modification program;

1. Identification of the problems.

2. Defining target behaviors.

3. Behavior recording.

4. Functional analysis.

5. Treatment procedures and their evaluation

In identification of problem we will make a list of problematic behavior (beating, head banging, wandering, abusing etc) of individual by using behavior checklist. In functional analysis we will analyze the relationship between a behavior and the immediate social environment. By a systematic enquiry into the $\mathrm{ABC}$ of behavior, A- Antecedents or events immediately before the behavior and environmental setting in which it occurs,B-Behavior, its frequency, duration and intensity, C- Consequences or events following behavior. In behavior procedures of management we will analyze the antecedent and consequences of behavior. Management will be planned for changing antecedents or consequences. Behaviormodification of decreasing undesirable behavior include - Restructuring the environment, Extinction, Punishment and Differential Reinforcement. Increasing desirable behavior can be done by three types of reinforces:

(a) Primary reinforcer- These are reinforcer which are essential for life (food, drink, sleep etc.) (b) Secondary reinforcer- These are the events or objects which have the property of a reinforcement (money, point) (c) Social reinforcer- These are the events which have significance at the emotional level (attention, smile, hugging).

\section{TECHNIQUES FOR INCREASING DESIRABLE BEHAVIOUR}

Token economy: token economy is a system of behavior modification based on the systematic reinforcement of target behavior. The reinforcers are symbols or "tokens" that can be exchanged for other reinforcers, Shaping. - build up a new behavior: This is a behavioral term 


\section{Mental Retardation an Overview}

that refers to gradually molding or training an organism to perform a specific response (behavior) by reinforcing any responses that are similar to the desired response, Prompting. :A prompt can be defined as a cue or hint meant to induce a person to perform a desired behavior. A fancy way of saying this is: An antecedent that induces a person to perform a behavior that otherwise does not occur. ,Fading: An action is gradually withdrawn until the need for it fades away, Chaining: It involves reinforcing individual responses occurring in a sequence to form a complex behavior, Imitation: Imitation is an advanced behavior whereby an individual observes and replicates another's behavior, Generalization: Generalization is a phenomenon in psychology where conditioned subjects respond to stimuli similar to those they were conditioned to respond to, Discrimination: The ability to perceive and respond to differences among stimuli.

\section{SUMMARY AND CONCLUSION}

Mental retardation have a long history and modified a lot in long run. Defnitions were made and modified. We cannot specify that one particular reason or cause is responsible for mental retardation. Many persons with mental retardation also have associated problems. Only very limited services were available in India until the period of the Colonial rule. Now we have our own screening tests, different programmes and schools. With the rights approach established through several legislations, the quality, accessibility, affordability and availability of an array of services have been strengthened. We have many approaches towards mental retardation and behavior modification is an important aspect.

\section{REFRENCES}

AAMD (1983) Mental Retardation. Retrived from http:/www.rehabcouncil.nic.in/writereaddata/mr.pdf on 1/11/2014.

10. Sparrow, Ballo, \& Cicchetti. (1984). in Kring, Johnson, Davinson, Neale.(11 ${ }^{\text {th }}$ ed.) (2010)Abnormal Psychology: Mental retardation. (pp.444-450). India: Wiley India.

AAMR (1983) Mental Retardation. Retrived from http:/www.rehabcouncil.nic.in/writereaddata/mr.pdf 2/11/2014.

American Psychiatric Association (2000) in Carson, R., Butcher, J., Mineka, S., \& Hooley. J(13 ${ }^{\text {th }}$ ed.) (2007) Abnormal psychology: Mental retardation. (pp 582-587). India: Pearson.

Down, L. (1866). in Carson, R., Butcher, J., Mineka, S \& Hooley, J(13 ${ }^{\text {th }}$ ed.) (2007). Abnormal psychology: Mental retardation.(pp 582-587). India: Pearson.

Kaski. (2000). in Carson, R., Butcher, J., Mineka, S. \& Hooley. J(13 ${ }^{\text {th }}$ ed.) (2007) Abnormal psychology: Mental retardation. (pp 582-587). India: Pearson.

Nihira, Foster, Shellhaas, \& Leland, (1975). in Kring., Johnson., Davinson., Neale., $\left(11^{\text {th }}\right.$ ed.) (2010) Abnormal Psychology: Mental retardation. (pp.444-450). Wiley India.

Penrose (1963). In Carson, R., Butcher, J., Mineka, S. \& Hooley. J(13 ${ }^{\text {th }}$ ed.) (2007) Abnormal psychology: Mental retardation. (pp 582-587). India: Pearson.

Rajamanikam, M. (2004). Abnormal Psychology human behavior problems: Mental retardation. (pp: 317-342). India, Tamil Nadu: Author Press.

Ricciuti.(1993). in Carson, R., Butcher. J., Mineka, S. \& Hooley. J(13 ${ }^{\text {th }}$ ed.) (2007) Abnormal psychology: Mental retardation. (pp 582-587). India: Pearson. 